\title{
Coincidence vs Cause: Cure in Three Glioblastoma Patients Treated with Brachytherapy
}

\author{
Amir R. Dehdashti, Sunjay Sharma, Normand Laperriere, Mark Bernstein
}

\begin{abstract}
Background: Very long term survival after diagnosis of malignant glioma has been described in individual case reports. Survival of more than 10 years is extremely rare, especially when identified in 3 out of 71 patients assigned to one arm of a randomized controlled trial. Patients: Three patients survived 11, 16, and 18 years following the diagnosis of glioblastoma and treatment with surgery, conventional fractionated radiation, and high-activity iodine-125 boost brachytherapy as part of a randomized controlled trial. Conclusion: Despite this apparent cause and effect relationship, statistical analysis shows no relationship between these cures and treatment with brachytherapy. Cure of glioblastoma remains rare.
\end{abstract}

RÉSUMÉ: Coïncidence vs cause : guérison chez trois patients atteints de glioblastome traités par brachythérapie. Contexte : Quelques patients ayant eu une survie très longue après un diagnostic de gliome malin ont été décrits antérieurement. Une survie de plus de 10 ans est extrêmement rare, d'autant plus qu'on l'a observée chez trois patients d'un groupe de 71 patients assignés au même bras d'une étude contrôlée randomisée. Observations : Trois patients ont survécu 11, 16 et 18 ans respectivement après le diagnostic de glioblastome et leur participation à une étude contrôlée randomisée comparant le traitement par chirurgie, radiothérapie fractionnée conventionnelle et brachythérapie par l'iode-125 comme source de radioactivité de haute activité. Conclusion : Malgré qu'il semble exister ici une relation de cause à effet, l'analyse statistique n'a pas montré de relation entre ces cas de guérison et le traitement par brachythérapie. Les cas de guérison du glioblastome demeurent rares.

Can. J. Neurol. Sci. 2007; 34: 339-342

Although surgical resection plays an integral role in the treatment of malignant gliomas, infiltration of tumor cells into surrounding brain prohibits cure by resection alone., ${ }^{1,2}$ Radiotherapy has been shown to improve local control and survival in patients with malignant gliomas. ${ }^{1,3}$ Chemotherapy has also been shown to improve survival and recently a multicenter trial demonstrated that radiation administered concomitantly with temozolomide confers a survival benefit with a two year survival of $26 \%$ as compared to $10.4 \%$ with radiotherapy alone. ${ }^{4}$ In the same setting, patients with glioblastoma containing a methylated MGMT promoter benefited more from temozolomide therapy. ${ }^{5}$ The prognosis for glioblastoma (GBM) has been, and remains however, extremely poor. Median length of survival remains about 14 months and has not changed significantly in the past 20 years. Unfortunately, nearly all patients will have either rapid tumor progression or recurrence despite aggressive multimodality approaches. Tumor recurs in 75 to $90 \%$ of patients within $2 \mathrm{~cm}$ of the resection margin and almost never outside of the central nervous system. ${ }^{6-8}$ Only $2.2 \%$ of patients diagnosed with GBM have a survival greater than 3 years. $^{9}$

Temporary interstitial brachytherapy allows the precise delivery of a large dose of localized radiation to the region with the highest concentration of infiltrating tumor cells, offering the prospect of improving local control. This modality was appealing in the 1980's and 1990's because of the high spatial localization of the dose and the favorable therapeutic ratio afforded by the low dose rate. ${ }^{10-12}$ There have been some reports

From the Division of Neurosurgery, Toronto Western Hospital, University of Toronto, Toronto, Ontario, Canada.

Received January 8, 2007. Accepted in Final fORm April 7, 2007.

Reprint requests to: Mark Bernstein, Division of Neurosurgery, Toronto Western Hospital, 399 Bathurst Street, 4th floor, West Wing, Toronto, Ontario, M5T 2S8, Canada 
of enhanced survival benefit with interstitial I-125 brachytherapy. ${ }^{10,13}$ However, the favorable results were biased by a selective group of patient who had other prognostic features associated with longer survival. ${ }^{12,14}$ When studied in two randomized control trials, brachytherapy offered no significant survival benefit over conventional treatment. ${ }^{15,16}$

In this case study, we document and report three patients diagnosed with glioblastoma who received brachytherapy on the randomized study at our center who continue to enjoy survival for more than 10 years after diagnosis of the disease.

\section{Materials ANd Methods}

The randomized trial of brachytherapy was designed to compare conventional external radiation therapy alone vs. conventional radiation therapy plus a brachytherapy boost in patients with malignant gliomas, with the primary end point as overall survival. ${ }^{15}$ The inclusion criteria were as follows: 1) biopsy proven supratentorial malignant glioma; 2) age 18-70; 3 ) KPS $>70$; 4) no involvement of corpus callosum; and 5) maximum tumor diameter of $6 \mathrm{~cm}$.

The brachytherapy technique has previously been described. ${ }^{15}$ Briefly, brachytherapy was undertaken within two weeks of completing external-beam radiation therapy. Linear plastic catheters were inserted stereotactically and high activity iodine-125 seeds were afterloaded intraoperatively. The intention was to deliver an additional minimum peripheral tumor dose of 60 Gy to all enhancing disease. The study demonstrated no statistically significant difference in the survival curves in the two groups, with the median survival of 13.8 months in the brachytherapy group as compared to 13.2 months in the group without brachytherapy. However, three patients among 71 randomized to the brachytherapy group have survived for an unusually long period. No patients in the 69 patients randomized to the group with conventional radiotherapy alone have enjoyed long survival.

\section{Case 1}

A 43-year-old female presented in 1995 with headache and left sided mild hemiparesis. She underwent aggressive resection of a right parietal glioblastoma (which appeared typical on imaging and on histology which was reviewed by two neuropathologists). This was followed by conventional radiotherapy and interstitial brachytherapy. At last follow-up in August 2006 the patient has a grossly normal neurological status except for mild dysarthria and KPS of 80. Recent MRI shows some superficial enhancement over the right parietal area which has remained stable (Figure 1).

\section{Case 2}

A 57-year-old male presented in 1990 with a non-dominant sided parietal syndrome. Imaging showed a typical ringenhancing right parietooccipital glioblastoma (histological examination confirmed a typical glioblastoma and was reviewed by two neuropathologists). The patient underwent aggressive subtotal resection followed by radiotherapy and subsequently brachytherapy. At last follow-up in October 2006 he has significant gait impairment due to left leg weakness and sensory loss but is well-preserved congnitively. Recent MR, 16 years

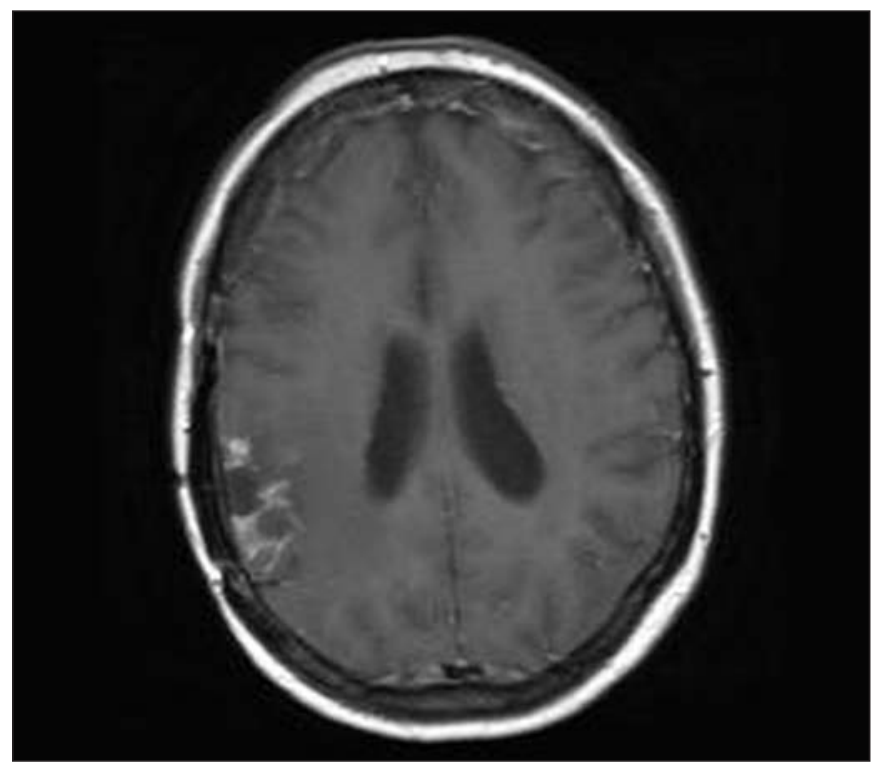

Figure 1: MRI with gadolinium injection 11 years after a surgical resection, external radiation, and brachytherapy for a right parietal glioblastoma in a presently 54-year-old patient. The slight parietal enhancement has been stable over many years and is most likely radiation necrosis.

after surgery shows an area of enhancement at the site of the tumor without mass effect, which has been stable over the last 15 years (Figure 2).

\section{Case 3}

A 33-year-old male patient presented in 1988 with headache and right sided homonymous hemianopia. Imaging showed a typical looking glioblastoma in the left occipital region and the patient underwent surgical resection of a glioblastoma which was confirmed by two neuropathologists. He was treated with boost brachytherapy and 24 months after brachytherapy underwent aggressive reoperation for predominantly radiation necrosis. The patient has remained well with KPS of 100 and MR follow-up remains devoid of tumor residue or recurrence.

\section{DISCUSSION}

Treatment of high grade gliomas remains a challenging clinical problem despite advances in neurosurgery, delivery of radiation, and novel chemotherapeutic agents. Radiation provides greater increases in survival than any other treatment modality. ${ }^{17}$ However increases in the radiation dose over 60 Gy have not resulted in additional improvement in survival. ${ }^{13}$ In the case of fractionated external beam radiotherapy, the lack of benefit from an additional dose is limited by injury to the normal brain. Brachytherapy was developed in an attempt to address 


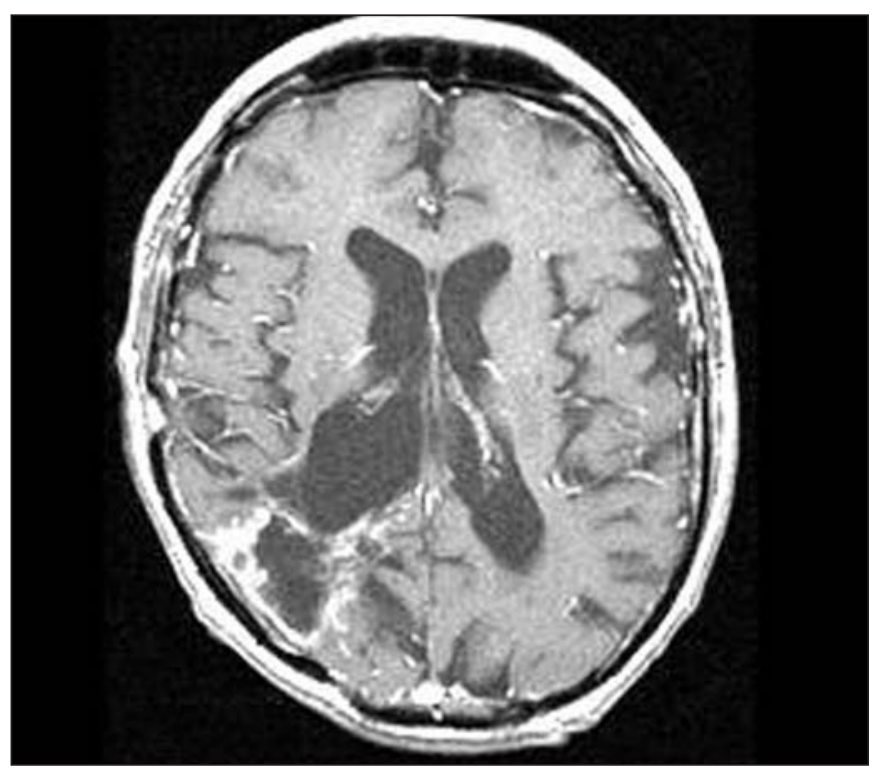

Figure 2: MRI 16 years after resection, conventional radiation, and brachytherapy of a right parietooccipital glioblastoma, in a presently 74 year-old man. There is some enhancement around the surgical site but no new change has been observed over the last 10 years.

some of these limitations. The promise of improved survival has been dampened by the high rate of radiation necrosis and tumor recurrence inspite of marginal improvement in local control, ${ }^{13,15,18-20}$ and fortunately at no significant cost to quality of life. ${ }^{21}$ Despite some encouraging results from a few single arm studies which reported an improved survival with brachytherapy, ${ }^{10,13,22}$ the results of the two randomized studies were disappointing, showing that brachytherapy offers no significant improvement of survival. ${ }^{15,16}$ Recently a multiinstitutional Gliasite brachytherapy trial showed a modest survival benefit in a group of patient with recurrent malignant gliomas. ${ }^{23}$

It has been reported that aggressive treatment of GBM is associated with a survival benefit while conventionally treated patients with GBM have both a short median survival and a very small chance of long term survival. ${ }^{9}$ Also, when examining characteristics that are associated with better outcome, younger age (mean 43.5) and KPS $>70$ prove to be important predictors. ${ }^{9}$ The usefulness of maximal surgical resection is unknown as no prospective randomized trial has been done, although some studies conclude that patients having aggressive tumor resection have longer survival..$^{9,24,25}$ Histological characteristics that are associated with enhanced survival include fewer mitotic figures as well as a lower $\mathrm{Ki}-67$ score and the presence of oligodendroglial features. ${ }^{26}$ Nevertheless, the median survival in all these patients does not exceed 18 to 20 months in the best situation.

The new molecular studies analyzing the methylation status of the MGMT show a significant but modest augmentation of survival. Among patients whose tumor contained a methylated MGMT promoter, a survival benefit was observed in patients treated with temozolomide and radiotherapy. Their median survival was 21.7 months, as compared with 15.3 months among those who were assigned to radiotherapy only. ${ }^{5,27}$ Those who did not have a methylated MGMT promoter did not have a statistically significant prolongation of survival from the combination of temozolomide and radiotherapy.

In the 71 patients randomized to brachytherapy along with surgery and radiotherapy, we were able to find three survivors essentially cured of disease whereas in the 69 patients randomized to the surgery and radiotherapy group, there were no long term survivors (maximum survival 26 months). These three patients had typical glioblastomas on imaging and histological examination but we have no molecular analysis of these tumors.

How should this interesting finding be interpretated? There is a $4.2 \%$ rate of long survival in the brachytherapy group as compared to 0 in the other group ( $\mathrm{p}=0.24$; Fisher's exact test). Very long-term survival after glioblastoma treatment has been described in individual cases, ${ }^{28-30}$ but this is the first study which reports a 4.2\% 10-year survival in a defined group of patients treated in a specific way. However, we cannot state that the prolonged survival is due to the treatment with brachytherapy and in fact the statistical analysis suggests no relationship. Whether these three patients represent a trend is matter for speculation only.

Is there a biologically or clinically select group of patients who enjoy an unusual survival rate? These three patients were differents in terms of sex, age, preoperative Karnofsky score, and even postoperative neurological status. The most important similarity was the relatively focal pattern of tumor enhancement. It would be important to find a specific subgroup of patients who might benefit from adjuvant brachytherapy (or other focused radiation) but the limited number of survivors in this study and the abovementioned substantial differences, make such an evaluation impossible. With newer magnetic resonance imaging techniques we may be able to identify patients with extremely focal disease who may stand to benefit from such focal agressive approaches. ${ }^{31}$

As pointed out above, radiation therapy has a prominent role in the treatment of primary intracranial malignant tumors. Although the long survival rate of $4.2 \%$ is a modest percentage in the brachytherapy group, this observation may warrant more attention to try to identify that subset of individuals with a higher likelihood of significant response to brachytherapy (or nowadays non-invasive focused high-dose radiation such as with radiosurgery). To date, there are no reports of very long survival following radiosurgery for glioblastomas.

Three very long-term survivors ( $>10$ years) with glioblastoma were identified in the brachytherapy arm of a randomized trial of brachytherapy used as a boost in the initial treatment of malignant glioma. Numbers are too few to be able to statistically define a subgroup that might have benefited from brachytherapy in this series, and the same limitation will obtain for observations of rare long-term survivors in other series. The authors are not recommending brachytherapy or other focused radiation modalities for the treatment of malignant gliomas based on these observations. The important message is for us clinicians to continue to make every attempt to identify subgroups of patients 
with better prognoses from aggressive therapies. It also reminds us to be ever aware that apparent cause and effect relationships in clinical medicine may still simply be coincidences.

\section{REFERENCES}

1. Mirimanoff RO, Gorlia T, Mason W, Van den Bent MJ, Kortmann RD, Fisher B, et al. Radiotherapy and temozolomide for newly diagnosed glioblastoma: recursive partitioning analysis of the EORTC 26981/22981-NCIC CE3 phase III randomized trial. J Clin Oncol. 2006;24:2563-9.

2. Wallner KE, Galicich JH, Krol G, Arbit E, Malkin MG. Patterns of failure following treatment for glioblastoma multiforme and anaplastic astrocytoma. Int J Rad Onc Biol Phys. 1989;16: $1405-9$.

3. Walker MD, Green SB, Byar DP, Alexander E, Batzdorf U, Brooks $\mathrm{WH}$, et al. Randomized comparisons of radiotherapy and nitrosoureas for the treatment of malignant glioma after surgery. N Engl J Med. 1980;303:1323-9.

4. Stupp R, Mason WP, van den Bent MJ, Weller M, Fisher B, Taphoorn MJ, et al. Radiotherapy plus concomitant and adjuvant temozolomide for glioblastoma. N Engl J Med. 2005;352: 987-96.

5. Hegi ME, Diserens AC, Gorlia T, Hamou MF, de Tribolet N, Weller $\mathrm{M}$, et al. MGMT gene silencing and benefit from temozolomide in glioblastoma. N Engl J Med. 2005;352:997-1003.

6. Bashir R, Hochberg F, Oot R. Regrowth patterns of glioblastoma multiforme related to planning of interstitial brachytherapy radiation fields. Neurosurgery. 1988;23:27-30.

7. Sneed PK, Gutin PH, Larson DA, Malec MK, Phillips TL, Prados $\mathrm{MD}$, et al. Patterns of recurrence of glioblastoma multiforme after external irradiation followed by implant boost. Int J Rad Onc Biol Phys. 1994;29:719-27.

8. Albert FK, Forsting M, Sartor K, Adams HP, Kunze S. Early postoperative magnetic resonance imaging after resection of malignant glioma: objective evaluation of residual tumor and its influence on regrowth and prognosis. Neurosurgery. 1994;34: 45-60.

9. Scott JN, Rewcastle NB, Brasher PM, Fulton D, MacKinnon JA, Hamilton M, et al. Which glioblastoma multiforme patient will become a long-term survivor? A population-based study. Ann Neurol. 1999;46:183-8.

10. Hitchon PW, VanGilder JC, Wen BC, Jani S. Brachytherapy for malignant recurrent and untreated gliomas. Stereotact Funct Neurosurg. 1992;59:174-8

11. Leibel SA, Gutin PH, Wara WM, Silver PS, Larson DA, Edwards MS, et al. Survival and quality of life after interstitial implantation of removable high-activity iodine-125 sources for the treatment of patients with recurrent malignant gliomas. Int $\mathbf{J}$ Rad Onc Biol Phys. 1989;17:1129-39.

12. Patel S, Breneman JC, Warnick RE, Albright RE, Tobler WD, van Loveren HR, et al. Permanent iodine-125 interstitial implants for the treatment of recurrent glioblastoma multiforme. Neurosurgery. 2000;46:1123-8.

13. Prados MD, Gutin PH, Phillips TL, Wara WM, Sneed PK, Larson DA, et al. Interstitial brachytherapy for newly diagnosed patients with malignant gliomas: the UCSF experience. Int J Rad Onc Biol Phys. 1992;24:593-7.

14. Mayr MT, Crocker IR, Butker EK, Williams H, Cotsonis GA, Olson JJ. Results of interstitial brachytherapy for malignant brain tumors. Int J Oncol. 2002;21:817-23.

15. Laperriere NJ, Leung PM, McKenzie S, Milosevic M, Wong S, Glen J, et al. Randomized study of brachytherapy in the initial management of patients with malignant astrocytoma. Int J Rad Onc Biol Phys. 1998;41:1005-11.

16. Selker RG, Shapiro WR, Burger P, Blackwood MS, Arena VC, Gilder JC, et al. The Brain Tumor Cooperative Group NIH Trial 87-01: a randomized comparison of surgery, external radiotherapy, and carmustine versus surgery, interstitial radiotherapy boost, external radiation therapy, and carmustine. Neurosurgery. 2002;51:343-55.
17. Chang CH, Horton J, Schoenfeld D, Salazer O, Perez-Tamayo R, Kramer S, et al. Comparison of postoperative radiotherapy and combined postoperative radiotherapy and chemotherapy in the multidisciplinary management of malignant gliomas. A joint Radiation Therapy Oncology Group and Eastern Cooperative Oncology Group study. Cancer. 1983;52:997-1007.

18. Bernstein M, Laperriere N, Glen J, Leung P, Thomason C, Landon AE. Brachytherapy for recurrent malignant astrocytoma. Int $\mathbf{J}$ Rad Onc Biol Phys. 1994;30:1213-17.

19. Ling CC, Anderson LL, Shipley WU. Dose inhomogeneity in interstitial implants using 125I seeds. Int J Rad Onc Biol Phys. 1979;5:419-25.

20. Reardon DA, Akabani G, Coleman RE, Friedman AH, Friedman HS, Herndon JE, et al. Phase II trial of murine (131) I-labeled antitenascin monoclonal antibody 81C6 administered into surgically created resection cavities of patients with newly diagnosed malignant gliomas. J Clin Oncol. 2002;20:1389-97.

21. Bampoe J, Laperriere N, Pintilie M, Glen J, Micallef J, Bernstein M. Quality of life in patients with glioblastoma multiforme participating in a randomized study of brachytherapy as a boost treatment. J Neurosurg. 2000;93:917-26.

22. Wen PY, Alexander E, Black PM, Fine HA, Riese N, Levin JM, et al. Long term results of stereotactic brachytherapy used in the initial treatment of patients with glioblastomas. Cancer. 1994;73:3029-36.

23. Gabayan AJ, Green SB, Sanan A, Jenrette J, Schultz C, Papagikos $\mathrm{M}$, et al. GliaSite brachytherapy for treatment of recurrent malignant gliomas: a retrospective multi-institutional analysis. Neurosurgery. 2006;58:701-9.

24. Ammirati M, Vick N, Liao YL, Ciric I, Mikhael M. Effect of the extent of surgical resection on survival and quality of life in patients with supratentorial glioblastomas and anaplastic astrocytomas. Neurosurgery. 1987;21:201-6.

25. Lacroix M, Abi-Said D, Fourney DR, Gokaslan ZL, Shi W, DeMonte F, et al. A multivariate analysis of 416 patients with glioblastoma multiforme: prognosis, extent of resection, and survival. J Neurosurg. 2001;95:190-8.

26. Kraus JA, Wenghoefer M, Schmidt MC, von Deimling A, Berweiler $\mathrm{U}$, Roggendorf $\mathrm{W}$, et al. Long-term survival of glioblastoma multiforme: importance of histopathological reevaluation. J Neurol. 2000;247:455-60.

27. Dehdashti AR, Hegi ME, Regli L, Pica A, Stupp R. New trends in the medical management of glioblastoma multiforme: the role of temozolomide chemotherapy. Neurosurg Focus. 2006;20:E6.

28. Bucy PC, Oberhill HR, Siqueira EB, Zimmerman HM, Jelsma RK. Cerebral glioblastoma can be cured. Neurosurgery. 1985;16: 714-17.

29. Burzynski SR, Lewy RI, Weaver R, Janicki T, Jurida G, Khan M, et al. Long-term survival and complete response of a patient with recurrent diffuse intrinsic brain stem glioblastoma multiforme. Integr Cancer Ther. 2004;3:257-61.

30. Yoshida T, Kawano N, Oka H, Fujii K, Makazato Y. Clinical cure of glioblastoma - two case reports. Neurol Med Chir (Tokyo). 2000;40:224-9.

31. Price SJ, Jena R, Burnet NG, Hutchinson PJ, Dean AF, Pena A, et al. Improved delineation of glioma margins and regions of infiltration with the use of diffusion tensor imaging: an imageguided biopsy study. AJNR. 2006;27:1969-74. 